\title{
Evidence for Increased Sympatho-adrenomedullary Activity in Young Subjects with Borderline Hypertension
}

\author{
Yasushi Ito, M.D., Katsuyuki Ando, M.D., Hiroshi Noda, M.D. \\ AND Toshiro Fujita, M.D.
}

\begin{abstract}
Three different studies were performed to estimate the sympatho-adrenomedullary activity in young subjects with borderline hypertension (BHT, $\mathrm{n}=$ $40)$, compared with age-matched normotensive subjects $(N T, n=24)$. In the first study, 23 BHT and 9 NT were subjected to isometric stress by maintaining handgrip at the $30 \%$ level of maximal voluntary contraction for $3 \mathrm{~min}$. The response of plasma total catecholamines at the second and third min during the isometric exercise were greater in BHT than in NT $(98.9 \pm 24.3$ vs. $18.0 \pm 30.7$ and $93.0 \pm 12.6$ vs. $47.1 \pm 15.4 \mathrm{pg} / \mathrm{ml}$, respectively, $\mathrm{p}<0.05)$. In the second study, the effects of intravenous glucagon injection (1 USP unit) were studied in $12 \mathrm{BHT}$ and $9 \mathrm{NT}$. The increments of plasma epinephrine (E) at 2 and $3 \mathrm{~min}$ after injection were significantly greater in BHT than those in NT: $44.1 \pm 12.3$ vs. $5.1 \pm 4.4 \mathrm{pg} / \mathrm{ml}$, and $68.9 \pm 13.2$ vs. $32.1 \pm 8.9 \mathrm{pg} / \mathrm{ml}$, respectively, $\mathrm{p}<0.05$. In the last study, the pressor effects of intravenous norepinephrine (NE) infusion (100 and $200 \mathrm{ng} / \mathrm{kg} / \mathrm{min}$ for $15 \mathrm{~min}$ ) were examined in 17 BHT and 15 NT under three different sodium balances: regular customary diet, treatment with diuretics and high-sodium diet. Treatment with diuretics decreased and high-sodium diet increased the pressor response to NE in both groups, but there were no significant differences in NE reactivity between 2 groups throughout the study. The increments in mean blood pressure after NE infusion $(200 \mathrm{ng} / \mathrm{kg} / \mathrm{min})$ on the three experimental periods correlated significantly with their preinfusion plasma NE concentrations in both BHT and NT: $r=-0.58(\mathrm{p}<0.01)$ and $r=-0.54$ $(p<0.01)$, respectively. Neither the slopes of these regression lines nor their intercepts differed between the 2 groups. Thus, BHT had augmented responses of plasma catecholamine to both isometric exercise and glucagon stimulation without vascular hyperreactivity to NE. Evidence presented suggests that the responses of both sympathetic nervous system and adrenal medulla to stress are increased in BHT.
\end{abstract}

$\mathbf{Y}$ OUNG subjects with borderline hypertension (BHT) are at least three times more likely to develop established essential hypertension than age-matched normotensive subjects (NT) ${ }^{1,2}$

Key words:

Sympatho-adrenomedullary activity

Borderline hypertension

Handgrip

Glucagon

Norepinephrine infusion
Thus, BHT have been of particular interest to investigators because they may provide insight into the pathogenesis of essential hypertension. The majority of studies have reported increased average circulating norephinephrine (NE) levels in $\mathrm{BHT}^{3-5}$ and more recently some studies have reported higher epinephrine (E) levels in BHT or mildly hypertensive patients. ${ }^{-7}$ Moreover, several investigators have demonstrated that, in BHT, there is an increased response of plasma

Department of Internal Medicine, Institute of Clinical Medicine, University of Tsukuba, Ibaraki, Japan

Mailing address: Toshiro Fujita, M.D., 4 th Department of Internal Medicine, University of Tokyo School of Midicine, 3-28-6 Mejirodai, Bunkyo-ku, Tokyo 112, Japan 
catecholamine to mental stress, ${ }^{8,9}$ or orthostatic tilting, ${ }^{10}$ suggesting a net increase in the sympatho-adrenal tone.11 These observations led us to the hypothesis that not only increased sympathetic activity but also adrenomedullary hyperactivity may be involved in the development of essential hypertension. To assess the sympathoadrenomedullary activity in BHT, two clinical studies were performed as follows: one was the responsiveness of plasma catecholamines during handgrip mainly to estimate the sympathetic activity 12 and the other was that of plasma $E$ during stimulation with the injection of glucagon chiefly to estimate adrenomedullary activity $!^{13}$

There are some reports indicating that BHT and NT with positive family history of hypertension are associated with increased pressor responses to exercise ${ }^{14}$ and emotional stress $8,9,15,16$ These increased pressor responsiveness might be attributed to either the release of catecholamines to stress or the increased vascular reactivity to endogenous catecholamine. In terms of vascular reactivity, however. It is still controversial whether or not BHT have increased pressor responsiveness to exogenous NE! ${ }^{1-21}$ We have studied the pressor response to NE under three different sodium balances; regular customary diet, treatment with diuretics and high-sodium diet.

\section{METHODS}

Sixty-four male subjects (40 BHT and 24 agematched normotensive subjects) were included in this study. Each subject underwent a physical examination and gave a medical history. Laboratory results, including urinalysis, serum electrolyte levels, plasma renin activity (PRA), and plasma aldosterone concentration, and results of electrocardiographic examination were normal. Thus, there was no evidence of a known cause of hypertension in any of BHT. At first visits of the trial, all subjects brought with them two complete $24 \mathrm{~h}$ urine samples for the determination of daily sodium excretions. Most had never been treated and in those few who had, antihypertensive drugs had been discontinued at least 2 months before the study. No patient was older than 30 years of age, and none had electrocardiographric or radiographic evidence of left ventricular hypertrophy, hypertensive retinopathy, or renal involvement. Each subject was informed of the nature of the study and gave written consent. Patients were considered to have borderline hypertension if, on examination in the outpatient department, their diastolic pressure at times exceeded but at other times were lower than $90 \mathrm{mmHg}$ !, 5

Study 1: The subjects were studied on an outpatient basis, and each subject attended a special research clinic for examination at a fixed hour and day of the week. After screening visits, 23 BHT and 9 NT were admitted to the trial. Indwelling catheters filled with heparinized saline were placed in both antecubital veins; one for blood sampling, and another for the injection of glucagon. Blood pressure and pulse rate were measured serially by an automated sphygmomanometer (Dinamap 845XT, Critikon, Florida, USA) every $1 \mathrm{~min}$. After a $30 \mathrm{~min}$ observation period, blood was drawn for the measurement of plasma catecholamines, PRA, and aldosterone concentration, and then isometric stress test was performed by maintaining handgrip at the 30\% level of maximal voluntary contraction for $3 \mathrm{~min}$. The blood pressure and pulse rate were then measured at $1 \mathrm{~min}$ intervals, and blood specimens for determination of plasma catecholamines were obtained at 1,2, and 3 min after the beginning of the stress test. Moreover, 20 min after the handgrip test, $1.0 \mathrm{mg}$ of glucagon (Novo Industri $\mathrm{A} / \mathrm{S}$, Copenhagen, Denmark) was injected intravenously as a bolus in 12 BHT and 9 NT. Then blood pressure and pulse rate were measured by the same procedure, and blood sampling was done at $1,2,3,5$, and $10 \mathrm{~min}$ after the injection of glucagon for determination of plasma catecholamines.

Study 2: After screening visits, $17 \mathrm{BHT}$ and 15 NT were admitted to the trial. Each subject underwent three consecutive studies. Hemodynamic and endocrine measurements were made while subjects maintained regular customary diets (normal-sodium diet), after sodium depletion with the administration of a diuretic $(25 \mathrm{mg} /$ day mefruside) for 1 week (diuretic treatment), and subsequently after $180 \mathrm{mEq}$ sodium chloride each day was added as $10 \mathrm{mEq}$ sodium chloride tablets for 1 week (high-sodium diet). A dietitian advised them on their diets based on their previous dietary histories to keep up a constant sodium and potassium intake without altering caloric intake. An indwelling catheter was placed in the antecubital vein through which $5 \%$ dextrose was slowly infused at a rate of $0.5 \mathrm{ml} / \mathrm{min}$ (Harvard Infusion Pump, Harvard Apparatus Co., Natick, MA, U.S.A.) while subjects were kept at rest in a supine position. This catheter was also used for the infusion of NE. Another indwelling 
TABLE I CLINICAL AND LABORATORY FINDINGS IN BORDERLINE HYPERTENSIVES (BHT) AND AGE-MATCHED NORMOTENSIVES (NT)

\begin{tabular}{|c|c|c|c|}
\hline & $B H T(n=40)$ & $N T(n=24)$ & \\
\hline Age (years) & $22 \pm 1$ & $20 \pm 1$ & $n s$ \\
\hline Mean blood pressure $(\mathrm{mmHg})$ & $88.3 \pm 1.2$ & $73.4 \pm 1.8$ & $p<0.01$ \\
\hline Pulse rate (beats $/ \mathrm{min})$ & $69.8 \pm 1.8$ & $61.8 \pm 1.5$ & $p<0.01$ \\
\hline Body weight $(\mathrm{kg})$ & $68.1 \pm 1.2$ & $67.9 \pm 1.5$ & $n s$ \\
\hline Urinary sodium ( $m E q /$ day) & $206 \pm 10$ & $244 \pm 20$ & $n s$ \\
\hline Plasma renin activity $(\mathrm{ng} / \mathrm{ml} / \mathrm{hr})$ & $2.1 \pm 0.2$ & $1.8 \pm 0.3$ & $n s$ \\
\hline Plasma aldosterone $(\mathrm{pg} / \mathrm{ml})$ & $106 \pm 7$ & $96 \pm 7$ & $n s$ \\
\hline
\end{tabular}

Values are represented as the mean $\pm S E$.

TABLE II INCREMENTS IN MEAN BLOOD PRESSURE, PULSE RATE AND PLASMA CATECHOLAMINES DURING 3-MIN HANDGRIP IN BORDERLINE HYPERTENSIVES (BHT) AND AGE-MATCHED NORMOTENSIVES (NT)

\begin{tabular}{|c|c|c|c|}
\hline & \multicolumn{3}{|c|}{ Increments } \\
\hline & $1 \mathrm{~min}$ & $2 \min$ & $3 \mathrm{~min}$ \\
\hline \multicolumn{4}{|c|}{ Mean blood pressure $(\mathrm{mmHg})$} \\
\hline$B H T(n=23)$ & $9.5 \pm 1.3$ & $11.9 \pm 1.4$ & $12.0 \pm 1.1$ \\
\hline$N T \quad(n=9)$ & $9.0 \pm 1.7$ & $12.4 \pm 2.1$ & $14.8 \pm 3.1$ \\
\hline \multicolumn{4}{|c|}{ Pulse rate (beats $/ \mathrm{min}$ ) } \\
\hline$B H T(n=23)$ & $6.6 \pm 1.1$ & $9.9 \pm 1.0$ & $13.9 \pm 1.1$ \\
\hline$N T \quad(n=9)$ & $6.2 \pm 1.8$ & $6.4 \pm 3.2$ & $8.2 \pm 2.3$ \\
\hline \multicolumn{4}{|c|}{ Plasma norepinephrine $(\mathrm{pg} / \mathrm{ml})$} \\
\hline$B H T(n=23)$ & $19.7 \pm 15.7$ & $60.0 \pm 17.3$ & $63.7 \pm 11.4$ \\
\hline$N T \quad(n=9)$ & $14.4 \pm 11.5$ & $9.0 \pm 20.7$ & $33.0 \pm 10.8$ \\
\hline \multicolumn{4}{|c|}{ Plasma epinephrine $(\mathrm{pg} / \mathrm{ml})$} \\
\hline$B H T(n=23)$ & $22.6 \pm 8.3$ & $38.8 \pm 10.5$ & $29.3 \pm 6.6$ \\
\hline$N^{\prime} T \quad(n=9)$ & $-5.0 \pm 4.7$ & $9.0 \pm 11.2$ & $14.1 \pm 6.2$ \\
\hline \multicolumn{4}{|c|}{ Total catecholamines $(\mathrm{pg} / \mathrm{ml})$} \\
\hline$B H T(n=23)$ & $42.2 \pm 18.6$ & $98.9 \pm 24.3^{a}$ & $93.0 \pm 12.6^{a}$ \\
\hline$N T \quad(n=9)$ & $9.4 \pm 13.7$ & $18.0 \pm 30.7$ & $47.1 \pm 15.4$ \\
\hline
\end{tabular}

Total catecholamines: plasma epinephrine plus norepinephrine. Values are represented as the mean \pm SE. a: $p<0.05$, compared with NT.

Mean blood pressure and pulse rate significantly increased during handgrip in both groups $(p<0.01)$. Plasma norepinephrine, epinephrine and total catecholamines significantly increased during handgrip in $B H T(p<0.05, p<0.05$ and $p<0.01$, respectively).

catheter filled with heparinized saline was inserted into the antecubital vein on the other side, used for blood collection. Blood pressure and pulse rate were measured serially by automated sphygmomanometer, as mentioned above, every $1 \mathrm{~min}$. At least $30 \mathrm{~min}$ after insertion of the indwelling catheters, but not before the patient was subjectively relaxed and had a stable pulse rate, blood for the determination of catecholamines was drawn. Then, following the infusion of $5 \%$ dextrose, the solution containing NE (Sankyo Co., Tokyo, Japan) was infused at $100(0.5 \mathrm{ml} / \mathrm{min})$ and $200(1.0 \mathrm{ml} / \mathrm{min}) \mathrm{ng} / \mathrm{kg} / \mathrm{min}$ through the indwelling catheter during consecutive 15 min periods. The experimental solution was brought to volume with $5 \%$ dextrose. 
TABLE III INCREMENTS IN MEAN BLOOD PRESSURE, PULSE RATE AND PLASMA CATECHOLAMINES AFTER GLUCAGON INJECTION IN BORDERLINE HYPERTENSIVES (BHT) AND AGE-MATCHED NORMOTENSIVES (NT)

\begin{tabular}{|c|c|c|c|c|c|}
\hline & \multicolumn{5}{|c|}{ Increments } \\
\hline & $1 \mathrm{~min}$ & $2 \min$ & $3 \min$ & $5 \mathrm{~min}$ & $10 \mathrm{~min}$ \\
\hline \multicolumn{6}{|c|}{ Mean blood pressure $(\mathrm{mmHg})$} \\
\hline$B H T(n=12)$ & $5.3 \pm 1.8$ & $7.1 \pm 1.7$ & $7.3 \pm 1.7$ & $2.1 \pm 1.1$ & $0.5 \pm 1.3$ \\
\hline$N T \quad(n=9)$ & $3.2 \pm 1.5$ & $6.5 \pm 1.9$ & $3.0 \pm 2.3$ & $2.4 \pm 2.0$ & $0.4 \pm 1.4$ \\
\hline \multicolumn{6}{|c|}{ Pulse rate (beats/min) } \\
\hline$B H T(n=12)$ & $6.2 \pm 1.3$ & $11.3 \pm 2.5$ & $6.5 \pm 1.9$ & $4.1 \pm 1.7$ & $1.6 \pm 1.6$ \\
\hline$N T \quad(n=9)$ & $7.6 \pm 3.0$ & $9.1 \pm 2.7$ & $4.6 \pm 2.6$ & $4.6 \pm 2.0$ & $-0.8 \pm 1.1$ \\
\hline \multicolumn{6}{|c|}{ Plasma epinephrine $(\mathrm{pg} / \mathrm{ml})$} \\
\hline$B H T(n=12)$ & $9.5 \pm 8.6$ & $44.1 \pm 12.3^{a}$ & $68.9 \pm 13.2^{a}$ & $46.2 \pm 11.8$ & $3.4 \pm 4.0$ \\
\hline$N T \quad(n=9)$ & $-3.8 \pm 3.6$ & $5.1 \pm 4.4$ & $32.1 \pm 8.9$ & $31.3 \pm 5.3$ & $6.8 \pm 4.6$ \\
\hline \multicolumn{6}{|c|}{ Plasma norepinephrine $(\mathrm{pg} / \mathrm{ml})$} \\
\hline$B H T(n=12)$ & $-4.8 \pm 11.0$ & $10.1 \pm 8.7$ & $14.3 \pm 10.7$ & $19.5 \pm 12.4$ & $18.5 \pm 11.6$ \\
\hline$N T \quad(n=9)$ & $-7.4 \pm 27.4$ & $-6.1 \pm 6.6$ & $14.3 \pm 9.0$ & $4.8 \pm 5.8$ & $15.3 \pm 8.0$ \\
\hline
\end{tabular}

Values are represented as the mean $\pm S E$.

a: $p<0.05$, compared with NT.

Mean blood pressure significantly increased 1 to $3 \mathrm{~min}$ in $B H T(p<0.01)$.

$P$ ulse rate and plasma epinephrine significantly increased 1 to $3 \mathrm{~min}$ in both groups $(p<0.05)$.

During the last $5 \mathrm{~min}$ of each infusion, blood pressure and pulse rate were measured every 1 min by sphygmomanometer, and the average of these parameters was defined as response of blood pressure or pulse rate at each infusion rate.

Laboratory procedures: Sodium concentrations in the urine were determined by flame photometry, utilizing lithium as an internal standard. Plasma renin activity and plasma aldosterone concentration were measured by radioimmunoassay. 2 Circulating $\mathrm{NE}$ and $\mathrm{E}$ were determined by the radioenzymatic method, as previously reported, 23 for study 1 and by trihydroxyindole methods after high performance liquie chromatography separation 24 for study 2 .

Statistical analysis: Numerical results are expressed as mean \pm standard errors of the mean (SE). Comparison of mean values between the groups was by the unpaired Student's t-test. For comparisons of mean values within study subgroups, analysis of variance, a priori comparison for comparisons to the basal values and a posteriori comparisons by the Sum of Squares Simultaneous Test Procedure (SS-STP) were used $^{25}$ And regression analysis according to the standard procedures and analysis of covariance were also included? ${ }^{26}$ Since natural logarithmic transformation rather than absolute values followed a Gaussian distribution, for statistical analysis we used the natural logarithmic transformation of the changes in plasma total catecholamines with handgrip. Differences at a $5 \%$ level $(p<0.05)$ were considered to be significant.

\section{RESULTS}

Table I summarizes clinical and laboratory findings in BHT and age-matched NT. There were no significant differences in respect to age or body weight in the two groups. In BHT significant increases existed in mean blood pressure and pulse rate as compared with those in the NT while there were no significant differences in PRA, plasma aldosterone concentration and urinary sodium excretion between the two groups.

Study 1: Plasma E showed marginally significant increase in BHT as compared with that in NT $(67 \pm 7$ vs. $48 \pm 8 \mathrm{pg} / \mathrm{ml}, \mathrm{p}<0.1)$, but there were no significant differences in plasma NE $(196 \pm 12$ in BHT vs. $212 \pm 19 \mathrm{pg} / \mathrm{ml}$ in NT) or plasma total catecholamines $(263 \pm 18$ in BHT vs. $261 \pm 24 \mathrm{pg} / \mathrm{ml}$ in NT). There was a significant correlation between plasma NE and plasma 


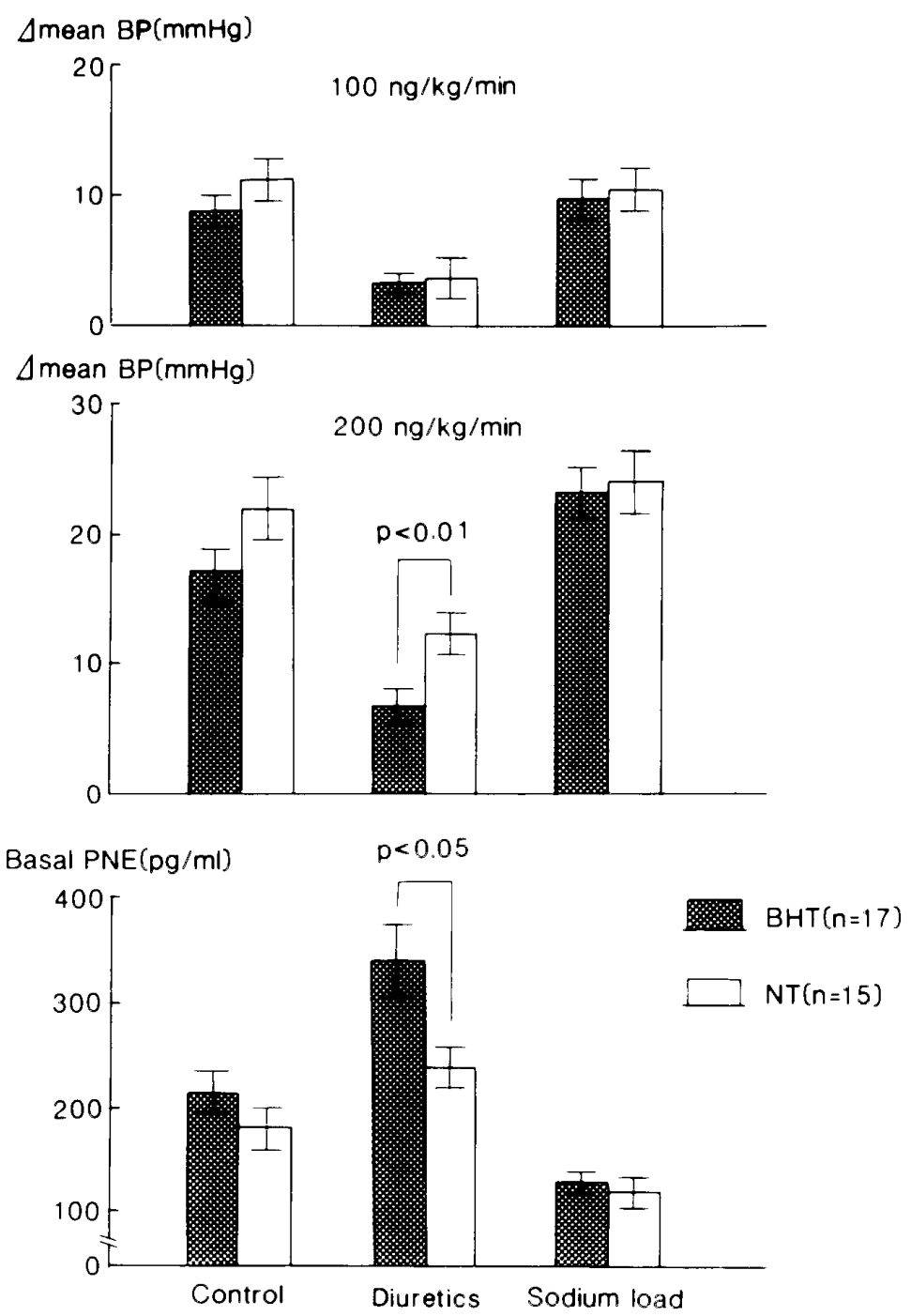

Fig.1. Pressor responses to norepinephrine (NE) infusion (top and middle panel) and basal plasma NE concentrations (PNE) (bottom) in 17 boderline hypertensives (BHT, closed columns) and 15 age-matched normotensives (NT, open columns) during a normal sodium diet (Control), during the administration of $25 \mathrm{mg} / \mathrm{day}$ mefruside for 1 week (Diuretics), and during dietary supplementation with $180 \mathrm{mEq} / \mathrm{day}$ sodium chloride (Sodium load).

E in all 23 BHT $(r=0.56, p<0.01)$.

During the handgrip exercise, the mean blood pressure $(p<0.01)$, and pulse rate $(p<0.01)$ increased promptly in the two groups and the degree of these parameters was not different in both BHT and NT (Table II). Indeed, the increments of plasma total catecholamines, when natural logarithmic transformation was performed, were significantly greater in BHT than in NT at the 2nd and 3rd min during handgrip $(98.9 \pm 24.3$ vs. $18.0 \pm 30.7 \mathrm{pg} / \mathrm{ml}$ and $93.0 \pm 12.6$ vs. $47.1 \pm 15.4 \mathrm{pg} / \mathrm{ml}$, respectively, $\mathrm{p}<0.05)$.

Table III shows the changes in plasma $E$ after stimulation with glucagon. Bolus intravenous injection of glucagon induced an immediate rise in pulse rate ( $\mathrm{p}<0.05$ in both groups), and plasma $E(p<0.05$ in both groups). Plasma $E$ reached a peak concentration 2 to $5 \mathrm{~min}$ after the injection of glucagon and thereafter declined rapidly to reach the base line level by $10 \mathrm{~min}$ after the injection in BHT and NT. Throughout the experimental period, however, plasma NE did not significantly change in both groups. There was no apparent difference with respect to timing of the response of plasma E in BHT and NT, but the response tended to be of greater magnitude in BHT than in the NT: the increments in plasma $\mathrm{E}$ at 2 and 3 min after glucagon were significantly greater in BHT than in NT: $44.1 \pm 12.3$ vs. $5.1 \pm 4.4 \mathrm{pg} / \mathrm{ml}$, and $68.9 \pm 13.2$ vs. $32.1 \pm 8.9 \mathrm{pg} / \mathrm{ml}$, respectively, $\mathrm{p}<0.05$. 
$\Delta$ mean $\mathrm{BP}(\mathrm{mmHg})$

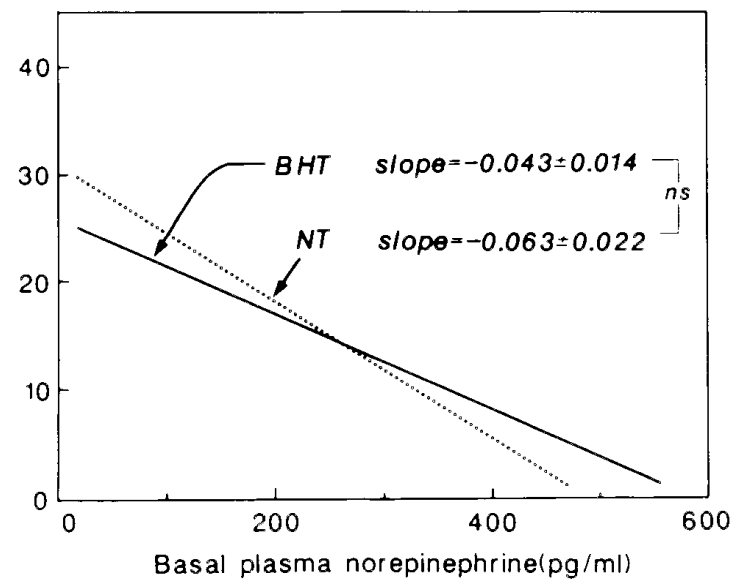

Fig. 2. In borderline hypertensives (BHT) and normotensives (NT) there were significant correlations between basal plasma norepinephrine concentrations (Abscissa) and the increments in mean blood pressure at $200 \mathrm{ngNE} / \mathrm{kg} / \mathrm{min}$ (Ordinate), the regression lines for the respective groups being $\mathrm{Y}=25.4-4.3 \times 10^{-2} \mathrm{X}$ (solid line) and $\mathrm{Y}=30.8-6.3 \times 10^{-2} \mathrm{X}$ (dotted line).

However, there were no significant differences in the changes of mean blood pressure or pulse rate with the injection of glucagon in BHT and NT.

Study 2: Borderline hypertensive subjects had a significant increase in mean blood pressure as compared with NT $(87.3 \pm 1.7$ vs. $69.9 \pm 2.0$ $\mathrm{mmHg}, \mathrm{p}<0.01$ ). These average mean blood pressures did not change with the administration of diuretics or after sodium loading in either group, while plasma NE concentration increased after diuretics and returned to the basal values on the last day of sodium loading in both BHT and NT. However, plasma NE concentration after diuretics was significantly higher in BHT than in NT (340 \pm 36 vs. $242 \pm 20 \mathrm{pg} / \mathrm{ml}, \mathrm{p}<0.05)$.

Figure 1 shows the average increments of mean blood pressure from basal level at each infusion rate of NE in BHT and in NT. The magnitude of the blood pressure change at each infusion rate was significantly less during the treatment with diuretics in both groups as compared to the other two experimental periods. There were no significant differences in the blood pressure responses to NE during two experimental periods of normal sodium diet and sodium loading between BHT and NT, whereas those to $200 \mathrm{ngNE} / \mathrm{kg} / \mathrm{min}$ on the diuretic treatment were significantly less in BHT who had higher basal concentrations of plasma NE than NT $(6.6 \pm 1.2 \mathrm{mmHg}$ in BHT vs. $12.3 \pm 1.7$ $\mathrm{mmHg}$ in NT, $\mathrm{p}<0.01)$.
As shown in Fig. 2, the increments in mean blood pressure with NE infusion at higher infusion rate throughout the three experimental periods did correlate significantly with the basal plasma NE levels of each period both in BHT and in NT $(\mathrm{r}=-0.58, \mathrm{p}<0.01$, and $\mathrm{r}=-0.54, \mathrm{p}<$ 0.01 , respectively). However, neither the slopes of the two regression lines $(-0.043 \pm 0.014$ in BHT vs. $-0.063 \pm 0.022$ in NT) nor their intercepts $(25.4 \pm 3.6$ in BHT vs. $30.8 \pm 4.3$ in NT) were statistically different between the two groups.

\section{DISCUSSION}

A number of observations have documented the importance of increased sympatho-adrenomedullary activity in the pathogenesis of essential hypertension; either plasma $\mathrm{E}$ or NE is increased in patients with essential hypertension.7 An increase in plasma NE reflects increased sympathetic activity, whereas an increase in plasma $E$ is likely to reflect an adrenal hyperactivity. Thus, it led us to the hypothesis that increased sympatho-adrenomedullary activity may play a important role in the development of established hypertension. Whereas there is agreement that an elevated plasma catecholamine concentration at rest can be demonstrated in a large proportion of patients with essential hypertension, it is still unknown whether this is the case in borderline hypertension $4,5,9,19-21,28,29$ In order to clarify whether or not BHT have the increased sympatho-adrenomedullary activity, the responses of sympathetic nervous system and adrenal medulla to two different stimulations, such as handgrip and glucagon injection, were examined.

Data obtained with the handgrip indicate that there were increased responses of plasma total catecholamines to the isometric exercise in BHT compared with those in NT, suggesting increased sympatho-adrenomedullary activity in borderline hypertension. Our results of plasma catecholamines are essentially similar to those of previous reports dealing with essential hypertension, indicating that increments in NE with exercise in the hypertensives were significantly greater than those in the normotensives. ${ }^{30}$ Despite the augmented responses of plasma catecholamines, these BHT did not have the increased pressor responses to handgrip. This is consistent with the results of a study dealing with middle aged essential hypertensives; there was no difference in the response of blood pressure with exercise 
between hypertensives and NT, in spite of augmented response of catecholamine in hypertensives. ${ }^{31}$ Another important findings from our study was that there was an increased response of plasma $\mathrm{E}$ to stimulation with glucagon in BHT as compared with that in NT. This finding is consistent with the results of a previous study showing that the response of urinary catecholamine to the intramuscular injection of glucagon was significantly increased in young hypertensive patients but not in elderly hypertensives. 32 Over the past 30 years, there has been a growing realization of the importance of the role of adrenomedullary function in the development and maintenance of animal and human hypertension. ${ }^{3-36}$ These observations indicated that increased adrenal catecholamine synthesis might contribute to the maintenance of high blood pressure and $\mathrm{E}$ might also be involved in the initiation of hypertension. Recently, much evidence has been presented suggesting that excessive release of peripheral catecholamines, especially $\mathrm{E}$, in response to stressful stimuli may play a role in the development of essential hypertension.,7

Although it could be demonstrated that excessive release of catecholamines to stress occurred in our BHT as in those with essential hypertension $^{30}$ the presence of augmented pressor response to endogenously released $\mathrm{NE}$ has been inconsecutive in borderline hypertension ${ }^{37}$ Indeed, some investigators found that the normotensive sons of hypertensive parents had increased responsiveness to $\mathrm{NE}^{38}$ while others have failed to demonstrate the augmented pressor responsiveness to NE or alpha agonist, phenylephrine, in $\mathrm{BHT}^{18,20}$ and prehypertensive subjects. ${ }^{39}$ The pressor responses to exogenous NE may depend upon several factors affecting vascular reactivity; age, endogenous catecholamine concentrations, ${ }^{40}$ structural or functional changes of vascular wall, 1 body sodium balance ${ }^{41}$ and so forth. It seems improbable that the advanced vascular lesions of severe hypertension would play any major role in the increased reactivity of blood vessels to pressor agents in young patients with minimally elevated blood pressure, a short history of disease, and no observable resultant functional impairment ${ }^{18}$ In addition, it is well known that daily sodium intake alters not only plasma NE concentration but also NE responsiveness to blood pressure in normal subjects; the pressor response to infused $\mathrm{NE}$ was increased 41 and the plasma concentration of NE significantly decreased after the period of high sodium intake $5,41,42$ When NE infusion study was performed under three different sodium balances, we are able to consider the relationship between these factors and pressor responses to exogenous NE. Our observation shows similar pressor response in BHT as in NT when we consider the basal plasma NE concentrations. In the present study it was clearly demonstrated that there was a negative correlation between resting plasma NE concentration and pressor effect of infused NE in BHT as in NT. Furthermore, neither the slopes nor the intercepts differed between BHT and NT. Evidence presented indicates that BHT do not have vascular hyperreactivity and that pressor responsiveness to NE depends partly upon basal sympathetic tone.

In summary, evidence presented suggests that the responses of sympathetic activity and adrenomedullary activity to stress are increased in BHT, but without the increased responses of blood pressure to exogenous NE. This augmented response of sympatho-adrenomedullary activity to stress might be involved in the development of essential hypertension.

\section{Acknowledgement}

Grateful acknowledgement is made to Prof. Kamejiro Yamashita, M.D. for his constant interest and guidance in this investigation.

\section{REFERENCES}

1. JULIUS S, ESLER M: Autonomic nervous cardiovascular regulation in borderline hypertension. $\mathrm{Am}$ J Cardiol 36: 685, 1975

2. FROHLICH ED, KOZUL VJ, TARAZI RC, DUSTAN HP: Physiological comparison of labile and essential hypertension. Circ Res 26/27 (Suppl I): 55,1970

3. COUSINEAU D, DE CHAMPLAIN J, LAPOINTE $\mathrm{L}$ : Circulating catecholamines and systolic time intervals in labile and sustained hypertension. Clin Sci Mol Med 55: 65s, 1978

4. MIURA Y, KOBAYASHI K, SAKUMA H, TOMIOKA $\mathrm{H}$, ADACHI $\mathrm{M}$, YOSHINAGA $\mathrm{K}$ : Plasma noradrenaline concentrations and hemodynamics in the early stage of essential hypertension. Clin Sci Mol Med 55: 69s, 1978

5. FUJITA T, NODA H, ANDO K: Sodium susceptibility and potassium effects in young patients with borderline hypertension. Circulation 69: 468, 1984

6. FRANCO-MORSELLI R, ELGHOZI JL, JOLY E, DI GIUILIO S, MEYER P: Increased plasma adrenaline concentration in benign essential hypertension. Br Med J 2: 1251, 1977

7. HORIKOSHI Y, TAJIMA I, IGARASHI H, INUI $M$, KASAHARA K, NOGUCHI T: The adrenosympathetic system, the genetic predisposition to 
hypertension, and stress. Am J Med Sci 289: 186, 1985

8. FALKNER B, KUSHNER $\mathrm{H}$, ONESTI $\mathrm{G}$, ANGELAKOS ET: Cardiovascular characteristics in adolescents who develop essential hypertension. Hypertension 3: 521, 1981

9. ELIASSON K, HJEMDAHL P, KAHAN T: Circulatory and sympatho-adrenal responses to stress in borderline and established hypertension. J Hypertension 1: 131, 1983

10. HULL DH, WOLTHUIS RA, CORTESE T, LONGO Jr MR, TRIEBWASSER JH: Borderline hypertension versus normotension: Differential response to orthostatic stress. Am Heart J 94: 414,1977

11. FOLKOW B: Physiological aspects of primary hypertension. Physiol Rev 62: 347, 1982

12. MARTIN CE, SHAVER JA, LEON DF, THOMPSON ME, REDDY PS, LEONARD JJ: Autonomic mechanisms in hemodynamic responses to isometric exercise. $J$ Clin Invest 54: 104, 1974

13. SCIAN LF, WESTERMANN CD, VERDESCA AS, HILTON JG: Adrenocortical and medullary effects of glucagon. Am J Physiol 199: 867, 1960

14. AOKI K, SATO K, KONDO S, PYON C, YAMAMOTO M: Increased response of blood pressure to rest and handgrip in subjects with essential hypertension. Jpn Circ J 47: 802, 1983

15. NESTEL PJ: Blood-pressure and catecholamine excretion after mental stress in labile hypertension. Lancet 1: 692, 1969

16. LIGHT KC, OBRIST PA: Cardiovascular reactivity to behavioral stress in young males with and without marginally elevated casual systolic pressure. Comparison of clinic, home, and laboratory measures. Hypertension 2: 802, 1980

17. EICH RH, CUDDY RP, BARRY JA, SMULYAN $\mathrm{H}$ : Blood concentration of catecholamines and their hemodynamic effects in man. Am $J$ Cardiol 10: 819,1962

18. SAFER ME, LONDON GM, WEISS YA, MILLIEZ PL: Vascular reactivity to norepinephrine and hemodynamic parameters in borderline hypertension. Am Heart J 89: 480, 1975

19. MEIER A, WEIDMANN P, GRIMM M, KEUSCH G, GLUCK Z, MINDER I, ZIEGLER WH: Pressor factors and cardiovascular responsiveness in borderline hypertension. Hypertension 3: 367, 1981

20. KAWANO Y, FUKIYAMA K, TAKEYA Y, ABE I, OMAE T: Elevated plasma catecholamines without alteration in cardiovascular responsiveness in young men with borderline hypertension. $\mathrm{Am}$ Heart $J$ 104: 1351, 1982

21. IIMURA O, KIKUCHI K, SATO S: Plasma noradrenaline concentration and pressor response to infused noradrenaline in patients with borderline hypertension, and mild or moderate essential hypertension. Jpn Circ J 48: 159, 1984

22. FUJITA $T$, ANDO $K$, NODA $H$, SATO $Y$, YAMASHITA N, YAMASHITA K: Hemodynamic and endocrine changes associated with captopril in diuretic-resistant hypertensive patients. $A m \mathrm{~J} \mathrm{Med}$ 73: 341,1982

23. FUJITA T, ANDO K: Hemodynamic and endocrine changes associated with potassium supplementation in sodium-loaded hypertensives. Hyperten. sion 6: 184, 1984

24. YAMATODANI A, WADA H: Automated analysis for plasma epinephrine and norepinephrine by liquid chromatography, including a sample cleanup procedure. Clin Chem 27: 1983, 1981

25. SOKAL RR, ROHLF FJ: Biometry. 2nd ed. W.H. Freeman and Company, San Francisco, USA, 1981

26. SNEDECOR GW, COCHRAN WG: Statistical methods, 6th ed. The Iowa State University Press, Ames, Iowa, USA, 1967

27 GOLDSTEIN DS: Plasma norepinephrine in essential hypertension: A study of the studies. Hypertension 3: 48, 1981

28. MESSERLI FH, FROHLICH ED, SUAREZ DH, REISIN E, DRESLINDKI GR, DUNN FG, COLE FE: Borderline hypertension: Relationship between age, hemodynamics and circulating catecholamines. Circulation 64: 760, 1981

29. MIURA Y, KOBAYASHI K, SAKUMA H, TOMIOKA $\mathrm{H}$, ADACHI $\mathrm{M}$, YOSHINAGA $\mathrm{K}$ : Plasma norepinephrine levels and hemodynamics in young patients with essential hypertension. Jpn Circ J 42: 609, 1978

30. GOLDSTEIN DS: Plasma norepinephrine during stress in essential hypertension. Hypertension 3: 551,1981

31. VLACHAKIS ND: Blood pressure and catecholamine responses to sympathetic stimulation in normotensive and hypertensive subjects. $J$ Clin Pharmacol 19: 458, 1979

32. MANDAI T, OGIHARA T, HATA T, OKADA Y, OGASAHARA S, MIKAMI H, NAKAMARU M, KUMAHARA Y: Urinary catecholamine response to glucagon in young and elderly patients with essential hypertension. $J$ Am Geriatr Soc 28: 462, 1980

33. SMITHWICK RH, THOMPSON JE: Splanchnictomy for essential hypertension. JAMA 152: 1501,1953

34. DE CHAMPLAIN J, MUELLER RA, AXELROD $\mathrm{J}$ : Turnover and synthesis of norepinephrine in experimental hypertension in rats. Circ Res 25: 285,1969

35. DE CHAMPLAIN J, VAN AMERIGEN MR: Regulation of blood pressure by sympathetic nerve fibers and adrenal medulla in normotensive and hypertensive rats. Circ Res 31: 617, 1972

36. MAJEWSKI H, TUNG LH, RAND MJ: Adrenalineinduced hypertension in rats. $J$ Cardiovasc Pharmacol 3: 179, 1981

37. SANNERSTEDT R, JULIUS S: Systemic haemodynamics in borderline arterial hypertension: responses to static exercise before and under the influence of propranolol. Cardiovasc Res 6: 398, 1972

38. BIANCHETTI MG, BERETTA-PICCOLI C, WEIDMANN P, FERRIER C: Blood pressure control in normotensive members of hypertensive families. Kidney Int 29: 882, 1986

39. KOTCHEN TA, GUTHRIE GP, McKEAN H, KOTCHEN JM: Adrenergic responsiveness in prehypertensive subjects. Circulation 65: 285, 1982

40. PHILIPP TH, DISTLER A, CORDES U: Sympathetic nervous system and blood-pressure control in essential hypertension. Lancet 2: 959, 1978 
41. RANKIN LI, LUFT FC, HENRY DP, GIBBS PS, WEINBERGER $\mathrm{MH}$ : Sodium intake alters the effects of norepinephrine on blood pressure. Hypertension 3: 650, 1981
42. NICHOLLS MG, KIOWSKI W, ZWEIFLER AJ, JULLIUS S, SCHORK MA, GREENHOUSE J: Plasma norepinephrine variations with dietary sodium intake. Hypertension 2: 29, 1980 